\title{
A Method to Evaluate Critical Factors for Successful Implementation of Clinical Pathways
}

\author{
W. Dong ${ }^{1}$; Z. Huang ${ }^{2}$ \\ ${ }^{1}$ Cardiology Department, Chinese PLA General Hospital, Beijing, China; ${ }^{2}$ College of Biomedical Engineering and Instrument \\ Science, Zhejiang University, Hangzhou, China
}

\section{Keywords}

Clinical pathway implementation, critical success factors, fuzzy DEMATEL, cause and effect

\section{Summary}

Objective: Clinical pathways (CPs) have been viewed as a multidisciplinary tool to improve the quality and efficiency of evidence-based care. Despite widespread enthusiasm for CPs, research has shown that many CP initiatives are unsuccessful. To this end, this study provides a methodology to evaluate critical success factors (CSFs) that can aid healthcare organizations to achieve successful CP implementation.

Design: This study presents a new approach to evaluate CP implementation CSFs, with the aims being: (1) to identify CSFs for implementation of CPs through a comprehensive literature review and interviews with collaborative experts; (2) to use a filed study data with a robust fuzzy DEMATEL (the decision making trial and evaluation laboratory) approach to visualize the structure of complicated causal relationships between CSFs and obtain the influence level of these factors. Participants: The filed study data is provided by ten clinical experts of a Chinese hospital. Results: 23 identified CSF factors which are initially identified through a review of the literature and interviews with collaborative experts. Then, a number of direct and indirect relationships are derived from the data such that different perceptions can be integrated into a compromised cause and effect model of $\mathrm{CP}$ implementation.

Conclusions: The results indicate that the proposed approach can systematically evaluate CSFs and realize the importance of each factor such that the most common causes of failure of $\mathrm{CP}$ implementation could be eliminated or avoided. Therefore, the tool proposed would help healthcare organizations to manage CP implementation in a more effective and proactive way.

\section{Correspondence to:}

Dr. Zhengxing Huang

College of Biomedical Engineering and Instrument

Science, Zhejiang University

Zhou Yiqin building 512

Zheda road 38

Hangzhou 310008, Zhejiang, China

Email: zhengxinghuang@zju.edu.cn

\section{Appl Clin Inform 2015; 6: 650-668}

http://dx.doi.org/10.4338/ACl-2015-05-RA-0054

received: May 11, 2015

accepted in revised form: September 13, 2015

published: November 4, 2015

Citation: Dong W, Huang Z. A method to evaluate critical factors for successful implementation of clinical pathways. Appl Clin Inform 2015; 6: 650-668 http://dx.doi.org/10.4338/ACl-2015-05-RA-0054 


\section{Introduction}

Clinical pathways (CPs), aiming to improve, in particular, the continuity and co-ordination of care across different disciplines and sectors, are one of the main tools used to manage the quality in healthcare concerning the standardization of care processes $[1-5,19,31]$. It has been shown that their implementation reduces the variability in clinical practice and improves outcomes $[1,6-8$, 32-34, 36].

However, the implementation of CPs may be not go well towards the expected direction [1, $12-14,33,35]$. On the contrary, it can be a risky proposition with potential for large investments but little or even an adverse effect upon outcomes. A number of studies have shown that a large percentage of CP implementation projects have been unsuccessful $[6,9-14,34]$. There are many factors to guarantee or even exaggerate the effectiveness of CPs. To achieve successful implementation of CPs, identifying and evaluating critical success factors (CSFs) is required. By CSFs identification, various potential organizational, technological, and operational factors that may influence CP implementation are uncovered to help healthcare organizations capture the source of the success of implementing a $\mathrm{CP}$, and to determine the corresponding solution to eliminate or avoid the most common causes of failure in implementing CPs.

There exist number of previous research focus on the reasons of failure of CP implementation and deciding the CSFs for CPs $[13-17,19,20,23]$. However, most of these researches used qualitative analysis to determine crucial factors of CP implementation in the hospitals. Having experts and managers evaluating these CSFs without a structured methodology becomes a difficult task and it incurs the inaccuracy in the process of determining the importance and classification of CSFs. To provide more accurate information as a valuable reference for CP implementation, it is necessary to develop a robust method that can systematically evaluate CSFs and realize the importance of each factor.

In this study, we propose a quantitatively oriented cognitive mapping approach for analyzing CSFs of CP implementation. The proposed approach can provide valuable information for cause and effect relationships. Through literature review and interviews with collaborative experts, CSFs of CP implementation are figured out. And also the description of the interrelationships among CSFs is given by clinical experts. Based on these field study data, we develop a fuzzy Decision Making Trial and Evaluation Laboratory (DEMATEL) method [18, 27, 28, 40] to evaluate CSFs of $\mathrm{CP}$ implementation and obtain the structure of complicated causal relationships and the influence level of these factors. DEMATEL is a powerful group decision making model to build the structural relationships among the strategic objectives for a strategy map, and can see the cause-effect relationship of criteria when measuring a problem [25-27, 39, 40]. Since the assigned preferences between the objectives are not crisp necessarily, and experts' domain knowledge can be extracted in a fuzzy environment in constructing a strategy map, the extended fuzzy DEMATEL can be applied to deal with the ambiguities inherent of such the judgments [26, 37]. The proposed fuzzy DEMATEL-based approach is advantageous in revealing the relationships among factors and prioritizing factors based on the type of relationships and severity of their effects on other factors of CP implementation.

The study was performed in the Cardiology Department at the Chinese PLA General hospital. Prior approval was obtained from the data protection committee of the hospital to conduct the study. We state that the patient data was anonymized in this study and in the Method section of this paper.

\section{Research methodology}

In this section, we propose a fuzzy DEMATEL model for building and analyzing a comprehensive model involving causal relationships between CSFs. The relationships can be used as a multi-level viewpoint of CP implementation. Before we go into detail with the application results of the technique and analysis, we explored CSFs for CP implementation. $>$ Figure 1 shows the procedure of the proposed fuzzy DEMATEL approach in this study. 


\subsection{Critical Success Factor Selection}

The literature mainly offers fairly similar and rather general CSFs for the performance of CP implementation [15-17, 20, 23], which may generally come from the four specific aspects, i.e. hospital administration level, clinical staff involvement and collaboration, patient condition and engagement, and healthcare information technology (HIT), respectively:

- Effective hospital administration plays an essential, critical and even strategic role for successful implementation of CPs. Hospital administration consists of establishing and planning activities for coordinating healthcare services in hospitals, and ensures that the implementation of CPs is well managed and specific outcomes are to be attained [21]. Consequently, there are many CSFs coming from hospital administration perspective, such as the level of "Hospital accreditation system", "Organization and management capacity of relevant departments", etc., which certainly affect the performance of CP implementation.

- Clinical staff, as the main participants or executors of CPs, determines the effectiveness of CP implementation. In fact, their cognitive level of CPs and their mastering capabilities on the pathways affect the performance of CP implementation significantly. On the one hand, it is expected that CPs are seen as a major management approach to enhancing clinical staff involvement by improving communication about daily goals between clinical staff, and increasing efficiency of care provided by clinical staff. On the other hand, clinical staff involvement and training help in acceptance of CPs. Additionally, clinical staff work together horizontally across multiple departments within the hospital, which requires inter-functional communication and collaboration [22]. To this end, effective communication and efficient collaboration among clinical staff is required before and during the implementation of CPs.

- A CP is a dynamically coordinated set of treatment activities or medical services that must be performed on particular patients in their careflow [32]. Due to the diversity of patient status even suffered from the same disease, CP implementation may differ to some extent for different patient individuals. For example, "Number of complications" is an essential factor that should be paid attention to, because patients suffering from the same disease but with more complications are more likely to have variations during CP execution. To this end, CP implementation is significantly affected by the conditions of patients who follow the pathways. In addition, the degree of patient engagement in CPs undoubtedly impacts the performance of CP implementation, as they are the targeted people who actually experience the CPs.

- HIT can provide new ways for healthcare providers and their patients to readily access and use health information, and has the potential to improve the quality, safety, and efficiency of healthcare $[24,38]$. HIT is important because it enables information sharing and efficient interoperability of medical and health information through information systems in hospital. Generally, there are paper-based CP and computerized CP in the hospital. With the development of HIT, paperbased CPs are gradually transformed to computerized CPs, which improves the interoperability efficiency of CPs [31]. Thus, HIT, as usually both the enabler and facilitator of CPs, has been recognized as an indispensable component to CP implementation [24]. Overlooking the role of HIT can result in failure of CP implementation, while appropriate HIT capabilities are particularly effective in realizing the other CSFs by integrating hospital managers, clinical staff, patients, and medical services together.

In this study, we take into account all variables arising from the hospital administration, clinical staff involvement and collaboration, patient conditions and engagement, and HIT to determine CSFs impacting the performance of CP implementation. Most variables are classified to one specific aspect while several other variables can be simultaneously classified into multiple different aspects. All possible CSFs affected the success of CP implementation are summarized in $>$ Table 1.

In general, CSFs are complex concepts, closely related, and difficult to measure. As well, CSFs are not easily tied to each other. As indicated in [25-27], causal analysis techniques are suitable tools to gather group knowledge of domain experts, to discover and visualize the structure of complicated causal relationships between CSFs, and to improve the quality of decision-making of organizations. An amount of studies have illustrated that causal analysis can greatly improve the efficiency of CSFs investigation and decision-making [26-28]. However, CSFs of CP implementation are typically 
complicated, unstructured and not readily quantifiable. Hence, the selected technique had to fulfill certain requirements. Table 2 lists several commonly used casual analysis techniques and the requirements demanded in the technique selection. When a certain technique fulfills a particular modeling requirement, this is indicated in Table 2 with $\sqrt{ }$.

As shown in $>$ Table 2, the fuzzy DEMATEL can satisfy all the requirements demanded, thus it has been selected in this study. The fuzzy DEMATEL is a hybrid method based on both fuzzy logic and the DEMATEL $[26,37]$. The DEMATEL is pragmatic to visualize the structure of complicated causal relationships with matrices or diagraphs [39]. It is a comprehensive method for building and analyzing a structural model involving causal relationships between complex factors [25-27]. Thus, non-additive methods, fuzzy measure and fuzzy integral are used to calculate the dependent criteria weights and the satisfaction value of each factor or aspect for fitting with the patterns of human perception. Note that human perceptions on decision factors are usually judged subjectively. In many practical cases, the human preference model is uncertain and might be reluctant or unable to assign exact numerical values to describe the preferences. To this end, the fuzzy DEMATEL method using linguistic expressions can be more effective for the expression of uncertainty in the decisionmaking process $[26,37]$. Regarding the problem of this study, the fuzzy DEMANTEL method is advantageous in revealing the relationships among CSFs along with the fuzzy pair-wise comparison of the factors in each level of the hierarchy, and prioritizing CSFs based on the type of relationships and severity of their effects on each other CSFs [27, 28]. By using fuzzy DEMATEL, clinical experts with no technical background can understand all of the components in CP implementation. They can identify and consider the most relevant factors that affect the performance of CP implementation. In addition, fuzzy DEMATEL has the ability to handle problems characterized by vagueness and impression, which is benefitted because the judgments of clinical experts on CSFs of CP implementation are often unclear and hard to estimate by exact numerical values [27, 28]. For these reasons, we think fuzzy DEMATEL is the most suitable technique to analyze CSFs of CP implementation.

\subsection{Clinical Experts Selection}

A fuzzy DEMATEL model represents multiple experts' knowledge [27, 28]. To avoid inconsistency and unreliability of the derived model, we recommend selecting a panel of domain experts to build and validate the final fuzzy DEMATEL model in this study.

In general, the greater the heterogeneity of the expert panel, the fewer the number of participants is recommended. A heterogeneous panel is understood to be a group of people with the same knowledge but on a different disciplinary or professional scale - which is what took place in this study. Hence, clinical experts with a diverse background in the development, maintenance and implementation of CPs were invited to participate on the panel to validate CSFs, which guarantees that the participants have a profound knowledge of CP implementation. As a result, ten clinical experts are carefully selected to make up of a heterogeneous panel, in the cooperation with Chinese PLA general hospital. The selected clinical experts belong to different disciplinary, i.e. two hospital managers, three physicians, three nurses, and two HIT technicians. These experts belong to different professional scales and have a rich knowledge and experience in the field of CP implementation. Owing to the diversity of the expertise of the selected experts, the panelists provided viewpoints from the perspective of a variety of relevant stakeholders.

\subsection{Methodology Application}

The proposed fuzzy DEMATEL method is composed of the following major steps:

Step 1: Constructing a fuzzy direct-relation matrix of CSFs for each clinical expert. It has four sub-steps:

Sub-step 1.1: Designing the fuzzy linguistic scale. To deal with the ambiguities of human assessments, the linguistic variable "influence" is used with five linguistic terms as no influence, very low influence, low influence, high influence, and very high influence that are expressed in a certain fuzzy membership functions, i.e., fuzzy numbers. Note that many fuzzy numbers have been used in fuzzy logic. Among these, the triangular fuzzy numbers are the most common in applications due to their 
computational simplicity, and their useful in promoting representation and information processing in a fuzzy environment [39]. In this study, we represent the linguistic variable "influence" by positive triangular fuzzy numbers $\left(l_{i j}, m_{i j}, r_{i j}\right)$, as shown in $>$ Table 3 . The empirical data are obtained from each individual expert assessment.

Sub-step 1.2: Acquiring the assessments of clinical experts and constructing a direct-relation matrix for each expert. Clinical experts were asked to develop sets of pair-wise comparisons in linguistic terms, which are used to measure the relationship between CSFs. As results, K fuzzy matrices were obtained ( $\mathrm{K}$ is the number of clinical experts, $\mathrm{K}=10$ in this study). For each fuzzy matrix provided by a specific clinical expert, it is denoted as:

$$
\tilde{Z}^{\mathrm{k}}=\left[\begin{array}{ccc}
\tilde{\mathrm{z}}_{11}^{k} & \cdots & \tilde{\mathrm{z}}_{1 n}^{k} \\
\vdots & \ddots & \vdots \\
\tilde{\mathrm{z}}_{m 1}^{k} & \cdots & \widetilde{\mathrm{z}}_{m n}^{k}
\end{array}\right]
$$

Where $\tilde{Z}_{\mathrm{ij}}^{\mathrm{k}}=\left(\mathrm{l}_{\mathrm{ij}}^{k}, m_{i j}^{k}, r_{i j}^{k}\right)$ are fuzzy values for the influence of the $\operatorname{CSF} f_{i}$ on the $\operatorname{CSF} f_{j}$ given by the expert $k$.

The fuzzy matrix $\quad \tilde{Z}^{\mathrm{k}}$ is established by the evaluation results of clinical experts on the pairwise influence relationships between CSFs. All the principal diagonal elements of $\tilde{Z}^{\mathrm{k}}$ are initially set to the value of zero (i.e. no influence).

Sub-step 1.3: Defuzzification of the direct-relation matrix. Defuzzification is required to get the weights of the CSFs. In this study, we adopted the CFCS (Converting Fuzzy data into Crisp Scores) defuzzification method for the fuzzy aggregation procedure [29]. The CFCS method is based on the procedure of determining the left and right scores by fuzzy min and fuzzy max, and the total score is determined as a weighted average according to the membership functions [29]. Briefly, the CFCS method is described as follows [29]:

Formally, let $\tilde{z}_{\mathrm{ij}}^{\mathrm{k}}=\left(\mathrm{l}_{\mathrm{ij}}^{k}, m_{i j}^{k}, r_{i j}^{k}\right)$ indicate the fuzzy assessments of expert $k$ about the degree to which the $\operatorname{CSF} f_{i}$ effects on the CSF $f_{j}$.

(1)Normalization:

$$
\begin{aligned}
\lambda_{i j}^{k} & =\left(l_{i j}^{k}-\min l_{i j}^{k}\right) / \Delta_{\min }^{\max } \\
\mu_{i j}^{k} & =\left(m_{i j}^{k}-\min l_{i j}^{k}\right) / \Delta_{\min }^{\max } \\
\rho_{i j}^{k} & =\left(r_{i j}^{k}-\min l_{i j}^{k}\right) / \Delta_{\min }^{\max }
\end{aligned}
$$

Where

$$
\Delta_{\min }^{\max }=\max r_{i j}^{k}-\min l_{i j}^{k}
$$

(2)Computing left and right normalized value:

$$
\begin{aligned}
& \omega_{i j}^{k}=\frac{\mu_{i j}^{k}}{1+\mu_{i j}^{k}-\lambda_{i j}^{k}} \\
& \psi_{i j}^{k}=\frac{\rho_{i j}^{k}}{1+\rho_{i j}^{k}-\mu_{i j}^{k}}
\end{aligned}
$$

(3)Computing total normalized crisp value:

$x_{i j}^{k}=\frac{\omega_{i j}^{k}\left(1-\omega_{i j}^{k}\right)+\psi_{i j}^{k} \psi_{i j}^{k}}{1-\omega_{i j}^{k}+\psi_{i j}^{k}}$

(4)Computing crisp value: $\mathrm{z}_{\min }^{\max }=\min l_{i j}^{k}+x_{i j}^{k} \Delta_{\min }^{\max }$ 
As a result, the crisp direct-relation matrix $Z^{\mathrm{k}}$ is derived:

$\mathrm{Z}^{\mathrm{k}}=\left[\begin{array}{ccc}z_{11}^{k} & \cdots & z_{1 n}^{k} \\ \vdots & \ddots & \vdots \\ z_{m 1}^{k} & \cdots & z_{m n}^{k}\end{array}\right]$

Sub-step 1.4: Combining all direct-relation matrices $Z^{1}, Z^{2}, \ldots, Z^{K}$ into an aggregate matrix using an averaging process as follows:

$\mathrm{Z}=\left(\sum_{\mathrm{k}=1}^{\mathrm{K}} Z^{k}\right) / K$

The aggregated direction relationship matrix of this study is shown in $>$ Table 4 .

Step 2: Constructing the normalized direct-relation matrix. On the basis of the aggregate directrelation matrix $\mathrm{Z}$, the normalized direct-relation matrix $\mathrm{N}$ can be obtained using the following expressions:

$$
\begin{aligned}
& \mathrm{N}=\mathrm{w} \cdot \mathrm{Z} \\
& \mathrm{w}=\frac{1}{\max \sum_{\substack{j=1 \\
1 \leq \mathrm{i} \leq \mathrm{n}}}^{n} z_{i j}}
\end{aligned}
$$

The matrix $\mathrm{N}$ of this study is shown in $>$ Table 5.

Step 3: Constructing the total relation matrix $(\mathrm{T})$ using the following expression:

The matrix of this study is shown in $>$ Table 6.

Step 4: Developing the causal influence and digraph diagram in DEMATEL. It consists of three sub-steps:

Sub-step 4.1: Determining row $\left(\mathrm{R}_{\mathrm{i}}\right)$ and column $\left(\mathrm{D}_{\mathrm{j}}\right)$ sums for each row $i$ and column $j$ from the total relation matrix $(\mathrm{T})$. These can be obtained using the following expressions:

$$
\begin{aligned}
& (j=1,2, \ldots, n)(15) \\
& (i=1,2, \ldots, n)(16)
\end{aligned}
$$

The row values $\mathrm{R}_{\mathrm{i}}$ represent the sum of direct and indirect influence by CSF $f_{i}$ on other CSFs of CP implementation. Similarly the column values $D_{j}$ show the sum of direct and indirect influence that $\mathrm{CSF} f_{j}$ is receiving from other CSFs.

Sub-step 4.2: Determining the overall importance or prominence of $\operatorname{CSF} f_{i}$ and net effect of $\operatorname{CSF} f_{j}$ using the following expressions:

The value of $\mathrm{P}_{\mathrm{i}}$ indicates the total cause of effect. The larger the value of $\mathrm{P}_{\mathrm{i}}$, the greater the overall prominence of CSF $f_{i}$ in terms of overall relationships with other CSFs. The value of $\mathrm{E}_{\mathrm{i}}$ indicates the net effect or cause of $f_{i}$. If $\mathrm{E}_{\mathrm{i}}>0, f_{i}$ is a net cause for other CSFs. If $\mathrm{E}_{\mathrm{i}}<0, f_{i}$ is a net effect of other CSFs. The results for CP implementation evaluation are shown in $>$ Table 7.

Sub-step 4.3: Developing the overall DEMATEL prominence-causal graphs. - Figure 1 shows a graphic of the overall prominence-causal relationships derived from $>$ Table 7 , on which we can observe general patterns and relationships amongst all CSFs. Due to the relatively large number of CSFs, we only mapped those relationships that are over a threshold value $\theta$. In this study, $\theta$ is empirically set as 0.16 . All the relationships that equal or larger than the threshold value are highlighted in the overall T matrix. The dynamic relationships are then plotted using dashed lines.

\section{Results}

Using the final results, we can identify the most important (prominent) factors and the most important relationships amongst CSFs of CP implementation. Prominence includes the integration of these factors from both cause (influencing) and effect (resulting) perspectives. This analysis can tell us from a temporal perspective which factors need to be in place in the initial stage of CP implemen- 
tation, and which ones require attention in the later stage of CP implementation. As follows, we separate and evaluate each of these relationships.

\subsection{Cause Factors}

From $>$ Figure 1, we can see that the four most important factors are the cognitive level of hospital administrators, hospital accreditation system, the cognitive level of clinical staff, and feedback of CP implementation. It is not surprising that the cognitive level of clinical staff is one of the most prominent factors. In general, the cognitive level of clinical staff is not only important factors for successful implementation of CPs, but also the most critical factors of medical quality and healthcare management, as indicated in many studies. Feedback of CP implementation, without any doubt, can help clinical staff in variation processing and posteriori analysis of CP variation by presenting the analysis result of CP implementation, so as to optimize and redesign CPs.

The cognitive level of hospital administrators and hospital accreditation system, with the highest score of , are primarily hospital-related. It strengthens the point that CP is not only an operational issue for medical service delivery, but also the strategic concern for healthcare organizations. They not only play a significant role in CP implementation, but also affect other CSFs. Note that the direction of significant influence between the cognitive level of hospital administrators and posteriori analysis of $\mathrm{CP}$ variation is unidirectional. The evaluation from this observation is that (1) cognitive level of hospital administrators needs to make sure that posteriori analysis of CP variation occurs, and (2) contribute to CP implementation when cognitive level of hospital administrators is in place.

In addition, other CSFs, e.g. records of pathway, feedback of CP implementation, etc. also influence posteriori analysis of CP variation. These are hospital-related factors that are in place to further make sure that the goals for posteriori analysis of CP variation. Note that prominence includes the integration of the factors from both a cause and effect perspective. This analysis can provide an ordinal perspective on what factors need to be considered initially (e.g. in CP design phase), and which ones require attention at a future time in CP implementation.

Besides, using the derived relationships among CSFs, we also found that the general understanding of CPs may be slightly different to clinical experts. For example, we notice that the way of payment for medical service is not the main cause for any other CSFs. As shown in DFigure 1, it has a standalone, less prominent presence when compared to other CSFs. This finding is interesting since CPs are in general recognized as a new channel for medical service payment in the hospital. This may indicate that, for successful implementation of CPs, healthcare organizations should pay their attention less on the "financial issue", but more on the relative importance of technicalities of hospital administration, cognitive level of hospital administrators and clinical staff, and usage of feedbacks of CP implementation, etc.

\subsection{Effect Factors}

The net effect CSFs, as the most influenced, resulting factors, may be the last ones a healthcare organization needs to address such that CP implementation achieves success. A net effect CSF can serve as the ultimate gatekeeper for the success of CP implementation. From $>$ Figure 1, we can identify several key net effect CSFs.

Management capacity of relevant departments, HIT support for CP, variation processing, and posteriori analysis of CP variation are not significant causes for any other CSFs while they are prominent CSFs. The significant causes of these three factors are very similar, including the cognitive level of hospital administrators, hospital accreditation system, the cognitive level of clinical staff, and feedback of CP implementation. Such results indicate that variation processing and posteriori analysis of CP variation, are generally serious issues at later stages in CP implementation, and can be addressed when the cognitive level of hospital administrators, hospital accreditation system, the cognitive level of clinical staff, and feedback of CP implementation are concerned in the early stage of CP implementation. Additionally, we find that the cognitive level of patients, adherence between computerized CPs and CP templates evidence for diagnosis and communications between patients and clinical staff are not related to any other CSFs, which indicates that these factors may require specific attention during CP implementation. 
A more in-depth check of Figure 2 shows that hospital accreditation system, the cognitive level of clinical staff, the cognitive level of hospital administrators, and feedback of CP implementation are four key cause factors on posteriori analysis of $\mathrm{CP}$ variation. It indicates that all these four factors contribute to assure that posteriori analysis of CP variation occurs when they are in place. Practically, if hospital managers and clinicians receive posteriori analysis results of $\mathrm{CP}$ variation, these four factors will help guarantee greater posteriori analysis of CP variation and greater CP implementation. Figure 1 also shows that feedback of CP implementation, as a key cause for posteriori analysis of $\mathrm{CP}$ variation, is also dependent on hospital accreditation system. It indicates that posteriori analysis of CP variation can be partly traced to poor strategic concern of healthcare organizations. For this small sample, the cognitive level of administrators was the most prominent CSF, followed by hospital accreditation system, which closely related to the basic situation of medical service delivery in hospitals in China.

\subsection{Research Implications}

The results present some initial guidance on successful implementation of CPs. It is benefited to distinguish whether a critical factor belongs to the cause group factors or the effect group. To reach a high level of performance of CP implementation, it requires a high level of focus on the cause group factors rather than the effect group. As shown in $>$ Figure 2, we have found that some CSFs are cause factors to successful implementation of CP. For example, the cognitive level of clinical staff needs to be developed for the general CPs. From a managerial perspective having cause factors CSFs being well addressed will be necessary to make sure that other CSFs are controlled at later stages in $\mathrm{CP}$ implementation. Appropriate planning and solutions can then be carried out to achieve a greater degree of success in CP implementation. But knowing which CSFs are cause factors and which ones are dependent is an important aspect of CP implementation that has rarely been investigated. The proposed methodology allows for this initial evaluation.

Note that the proposed method can be valuable for developing a series of research propositions. For example, we can make a proposition that there are direct and indirect effects of the cognitive level of hospital administrators on posteriori analysis of $\mathrm{CP}$ variation. The indirect relationship is that the relationship between the cognitive level of hospital administrators and posteriori analysis of $\mathrm{CP}$ variation is mediated by strategic alignment perceptions. In addition, with the proposed fuzzy DEMATEL method, the hospital can segment a list of CSFs into expressive groups for making decisions in the CP implementation initiative. According to the results of segmentation, it was revealed that the most crucial factors are the cognitive level of hospital administrators, and hospital accreditation system, not HIT. Although the cognitive level of hospital administrators and hospital accreditation system are not easy changed, they are the core part of promoting a successful CP implementation and the root of achieving high quality of medical service delivery in CPs. Hence, the hospital must emphasize the importance of the cognitive level of hospital administrators and hospital accreditation system to succeed in its CP implementation initiatives.

\section{Conclusion}

The results of this study indicate that the proposed method can measure importance of CSFs and the ordinal relationships among CSFs, so as to provide initial insights into CP implementation. This is quite helpful for hospital managers to identify critical factors that need to be focused upon for successful implementation of CPs. The proposed approach provides a basis for further studies, and we believe that there is ample opportunity to investigate how the proposed tool can be used to achieve successful CP implementation. In particular, the proposed approach can not only be used as a way to handle the interdependencies within a set of criteria, but also provide more valuable information for making decisions. The achievements of this study are expected to be of interest to the policy makers, health providers and HIT vendors. More customized and effective technological innovations can therefore be developed for successful implementation of CPs and to improve the quality of medical service delivery. 
For future studies, some limitations of the proposed approach will be underlined. What we have shown in this study is a static representation of the relationships between CSFs such that critical factors can be identified for successful implementation of CPs. Over time, the relationships between CSFs may change dynamically, and it requests to provide what-if analysis based on the dynamic behavior of CSFs. In addition, the accuracy of the proposed fuzzy DEMATEL is strongly dependent on the experts' judgments Note that experts may look insight into CPs from their unique perspectives, and thus, we cannot expect that the selected experts have the same perception on CPs. Inevitably, bias exists in the experimental dataset. Therefore, matters such as the selection of the panelists in the domain studied, the feedback with them, and the method used to build the tool are critical.

\section{Contributors}

WD: conception, design, extraction of data, interpretation and evaluation of results. ZH: conception, design and development of methods, and drafting of the manuscript. Both authors read and approved the final manuscript.

\section{Funding}

This work was supported by the National Nature Science Foundation of China under Grant No. 81101126 and 61562088, and the Fundamental Research Funds for the Central Universities under Grant No 2014QNA5014.

\section{Conflicts of interest}

The authors declare that they have no competing interests.

\section{Human Subjects Protections}

No human subjects were involved in the project.

\section{Data share statement}

No additional data are available. 


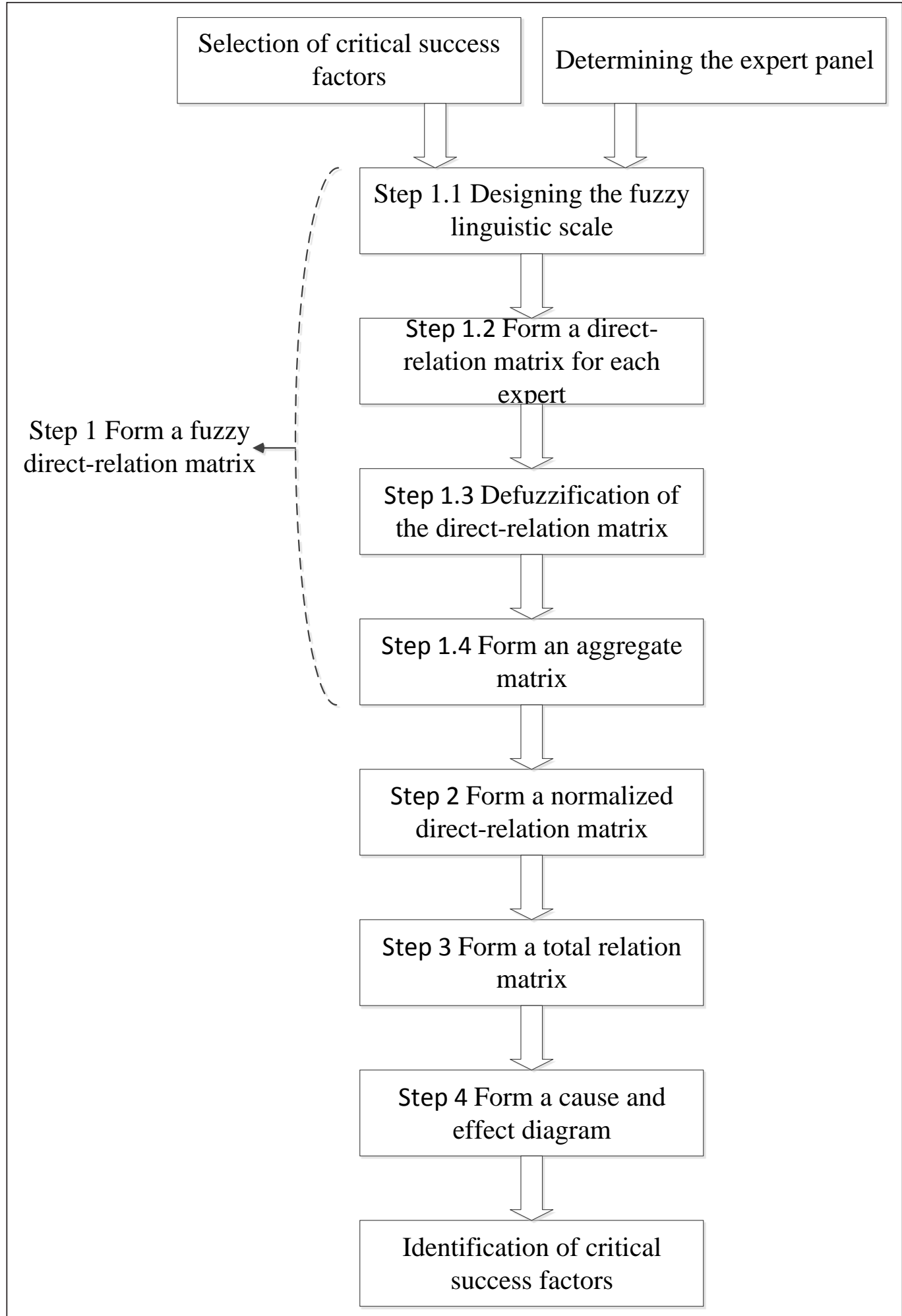

Fig. 1 The procedure of the proposed approach. 


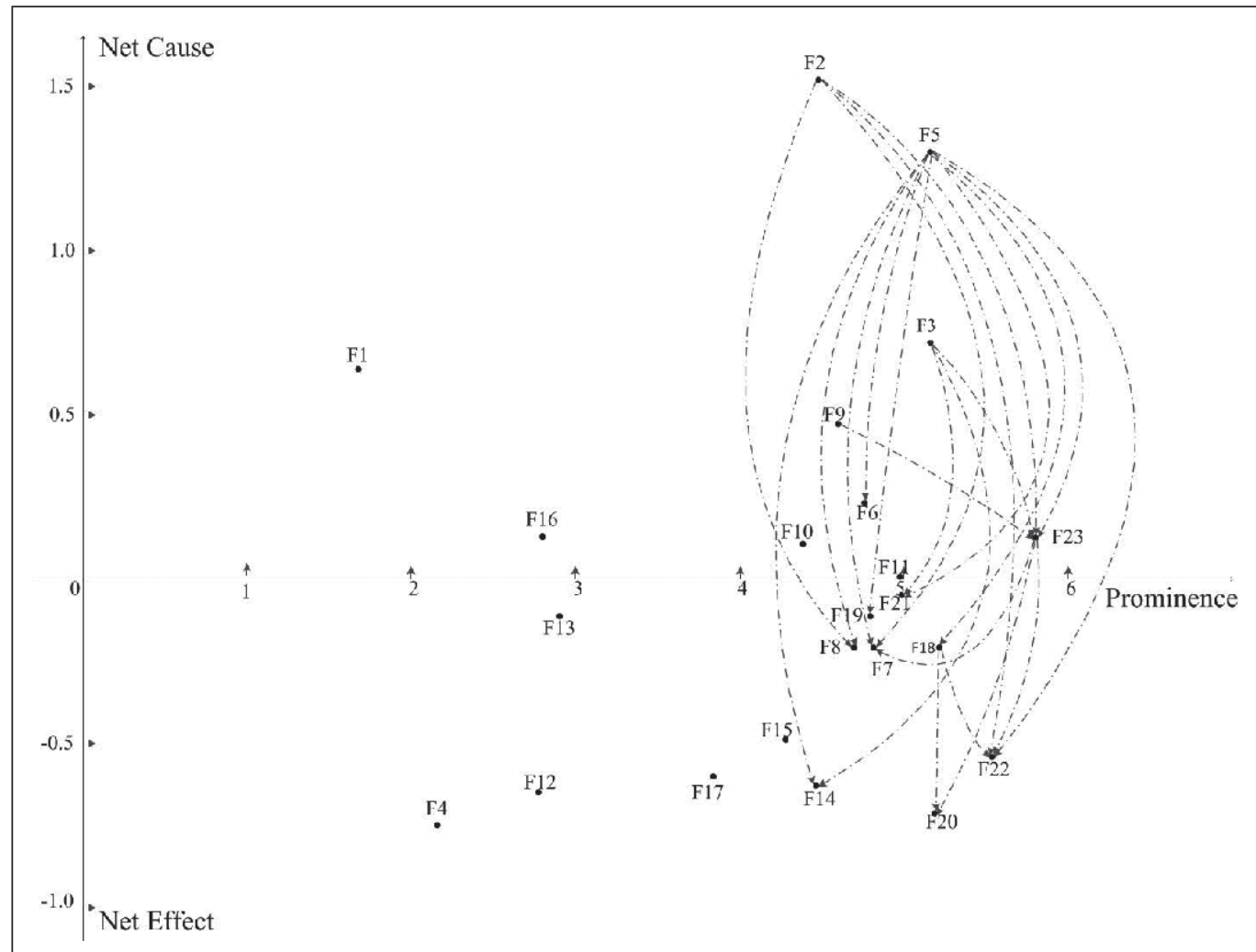

Fig. 2 Overall fuzzy DEMATEL prominence-causal relationship diagram. Some CSFs are cause factors to successful implementation of CP. For example, the cognitive level of clinical staff needs to be developed for the general CPs. From a managerial perspective having cause factors CSFs being well addressed will be necessary to make sure that other CSFs are controlled at later stages in CP implementation. 
Table 1 Critical factors for successful CP implementation.

\begin{tabular}{|c|c|c|c|}
\hline Label & Factor Name & Description & Classification \\
\hline$f_{1}$ & $\begin{array}{l}\text { The way of payment for } \\
\text { medical service }[20,30]\end{array}$ & $\begin{array}{l}\text { The way patients pay their medical service, } \\
\text { determined by the assurance owned by them }\end{array}$ & $\begin{array}{l}\text { Hospital administration } \\
\text { level / patient condition } \\
\text { and engagement }\end{array}$ \\
\hline$f_{2}$ & $\begin{array}{l}\text { Hospital accreditation } \\
\text { system [30] }\end{array}$ & $\begin{array}{l}\text { The ratio of applying CP in patient careflow is one } \\
\text { of the most important measures that has already } \\
\text { been adopted by health authority to evaluate the } \\
\text { level of hospital }\end{array}$ & $\begin{array}{l}\text { Hospital administration } \\
\text { level }\end{array}$ \\
\hline$f_{3}$ & $\begin{array}{l}\text { Cognitive level of clinical } \\
\text { staff }[3,12,16,20,23]\end{array}$ & $\begin{array}{l}\text { Clinical staff's awareness of the importance and } \\
\text { benefits of CPs }\end{array}$ & $\begin{array}{l}\text { Clinical staff involve- } \\
\text { ment and collaboration }\end{array}$ \\
\hline$f_{4}$ & $\begin{array}{l}\text { Cognitive level of } \\
\text { patients [12] }\end{array}$ & $\begin{array}{l}\text { Patients' awareness of the importance and } \\
\text { benefits of CPs }\end{array}$ & $\begin{array}{l}\text { Patient condition and } \\
\text { engagement }\end{array}$ \\
\hline$f_{5}$ & $\begin{array}{l}\text { Cognitive level of hospi- } \\
\text { tal administrators [12, } \\
\text { 16] }\end{array}$ & $\begin{array}{l}\text { The awareness of the importance and benefits of } \\
\text { CPs for the development of hospital held by } \\
\text { hospital administrators who may make } \\
\text { mobilization of clinical staff to be aware of the } \\
\text { importance and benefits of CP }\end{array}$ & $\begin{array}{l}\text { Hospital administration } \\
\text { level/ clinical staff } \\
\text { involvement and collab- } \\
\text { oration }\end{array}$ \\
\hline$f_{6}$ & $\begin{array}{l}\text { Working environment of } \\
\text { hospital for the imple- } \\
\text { mentation of CP }[8,16 \text {, } \\
20,24]\end{array}$ & $\begin{array}{l}\text { The basic working infrastructure for } \mathrm{CP} \\
\text { implementation consists of medical resource } \\
\text { equipment and knowledge equipment }\end{array}$ & $\begin{array}{l}\text { Hospital administration } \\
\text { level / clinical staff } \\
\text { involvement and collab- } \\
\text { oration }\end{array}$ \\
\hline$f_{7}$ & $\begin{array}{l}\text { Management capacity of } \\
\text { relevant departments }[12 \text {, } \\
16,20]\end{array}$ & $\begin{array}{l}\text { The distribution of medical resource and clinical } \\
\text { staff in relevant departments, and collaborations } \\
\text { between departments for the implementation of } \\
\text { CPs }\end{array}$ & $\begin{array}{l}\text { Hospital administration } \\
\text { level / clinical staff } \\
\text { involvement and collab- } \\
\text { oration }\end{array}$ \\
\hline$f_{8}$ & $\begin{array}{l}\text { HIT support for CP }[1,3 \text {, } \\
8,20,23,24]\end{array}$ & $\begin{array}{l}\text { Using HIT to support CP execution and improve } \\
\text { quality of CP }\end{array}$ & $\begin{array}{l}\text { Healthcare information } \\
\text { technology }\end{array}$ \\
\hline$f_{9}$ & $\begin{array}{l}\text { Establishment of respon- } \\
\text { sible office for CP imple- } \\
\text { mentation }[12,16,30]\end{array}$ & $\begin{array}{l}\text { responsible office for the implementation of CPs } \\
\text { to assess and increase the actual application ratio } \\
\text { of CPs in hospital }\end{array}$ & $\begin{array}{l}\text { Hospital administration } \\
\text { level }\end{array}$ \\
\hline$f_{10}$ & $\begin{array}{l}\text { Diseases for } \mathrm{CP} \text { execution } \\
\text { [1] }\end{array}$ & Choice of diseases that are suitable to perform CP & $\begin{array}{l}\text { Clinical staff involve- } \\
\text { ment and collaboration }\end{array}$ \\
\hline$f_{11}$ & $\begin{array}{l}\text { Quality of CP templates } \\
{[1,16,20]}\end{array}$ & Rationality of the workflow design for CPs & $\begin{array}{l}\text { Hospital administration } \\
\text { level /clinical staff } \\
\text { involvement and collab- } \\
\text { oration }\end{array}$ \\
\hline$f_{12}$ & $\begin{array}{l}\text { Adherence between com- } \\
\text { puterized CPs and CP } \\
\text { templates }[1,24]\end{array}$ & $\begin{array}{l}\text { The computerized CP should be adherent with the } \\
\text { established CP templates }\end{array}$ & $\begin{array}{l}\text { Healthcare information } \\
\text { technology }\end{array}$ \\
\hline$f_{13}$ & $\begin{array}{l}\text { Evidence for diagnosis }[1, \\
6,20]\end{array}$ & $\begin{array}{l}\text { The evidence recorded in CP templates which } \\
\text { clinical staff adopted to diagnosis the disease } \\
\text { patients were suffering }\end{array}$ & $\begin{array}{l}\text { Clinical staff involve- } \\
\text { ment and collaboration }\end{array}$ \\
\hline$f_{14}$ & $\begin{array}{l}\text { Evidence for therapy op- } \\
\text { tions }[1,6,20]\end{array}$ & $\begin{array}{l}\text { Evidence recorded in CP templates which clinical } \\
\text { staff adopted for choosing specific treatment } \\
\text { interventions in } \mathrm{CP} \text { execution }\end{array}$ & $\begin{array}{l}\text { Clinical staff involve- } \\
\text { ment and collaboration }\end{array}$ \\
\hline$f_{15}$ & $\begin{array}{l}\text { Standard for inclusion } \\
\text { and exclusion }[13,20]\end{array}$ & $\begin{array}{l}\text { Standard constraints patients entering } \mathrm{CP} \text { or } \\
\text { exiting } \mathrm{CP}\end{array}$ & $\begin{array}{l}\text { Clinical staff involve- } \\
\text { ment and collaboration }\end{array}$ \\
\hline$f_{16}$ & $\begin{array}{l}\text { Number of complications } \\
{[3,13]}\end{array}$ & $\begin{array}{l}\text { The number of complications patients were } \\
\text { suffering during the treatment process }\end{array}$ & $\begin{array}{l}\text { Patient condition and } \\
\text { engagement }\end{array}$ \\
\hline
\end{tabular}


Table 1 Continued

\begin{tabular}{|l|l|l|l|}
\hline Label & Factor Name & Description & Classification \\
\hline$f_{17}$ & $\begin{array}{l}\text { Communication between } \\
\text { clinical staff and patients } \\
{[20]}\end{array}$ & $\begin{array}{l}\text { Communication related to the treatment } \\
\text { procedure and new arising variation between } \\
\text { medical staff and patients }\end{array}$ & $\begin{array}{l}\text { Clinical staff involve- } \\
\text { ment and collaboration } \\
\text { / patient condition and } \\
\text { engagement }\end{array}$ \\
\hline$f_{18}$ & $\begin{array}{l}\text { Quality control during } \\
\text { pathway execution [20] }\end{array}$ & $\begin{array}{l}\text { Timely monitoring of the medical quality during } \\
\text { pathway execution }\end{array}$ & $\begin{array}{l}\text { Clinical staff involve- } \\
\text { ment and collaboration }\end{array}$ \\
\hline$f_{19}$ & $\begin{array}{l}\text { Records of pathway [1, } \\
13,20]\end{array}$ & $\begin{array}{l}\text { Recording medical interventions and patient } \\
\text { behaviors related to the treatment process }\end{array}$ & $\begin{array}{l}\text { Clinical staff involve- } \\
\text { ment and collaboration }\end{array}$ \\
\hline$f_{20}$ & $\begin{array}{l}\text { Variation processing }[6, \\
20]\end{array}$ & $\begin{array}{l}\text { Measures clinical experts taken to handle the } \\
\text { variation during the treatment process }\end{array}$ & $\begin{array}{l}\text { Clinical staff involve- } \\
\text { ment and collaboration }\end{array}$ \\
\hline$f_{21}$ & $\begin{array}{l}\text { Evaluation indicators }[6, \\
20]\end{array}$ & $\begin{array}{l}\text { Determine the indicators used to evaluation the } \\
\text { implementation of CP and quality of CP }\end{array}$ & $\begin{array}{l}\text { Clinical staff involve- } \\
\text { ment and collaboration }\end{array}$ \\
\hline$f_{22}$ & $\begin{array}{l}\text { Posteriori analysis of } C P \\
\text { variation }[1,6,20]\end{array}$ & $\begin{array}{l}\text { Analysis the data related to variations recorded in } \\
\text { treatment process after the implementation of CP }\end{array}$ & $\begin{array}{l}\text { Clinical staff involve- } \\
\text { ment and collaboration }\end{array}$ \\
\hline$f_{23}$ & $\begin{array}{l}\text { Feedback of CP imple- } \\
\text { mentation }[1,6,20]\end{array}$ & $\begin{array}{l}\text { Present implementation result of CPs to clinical } \\
\text { experts to help them optimize and redesign CPs }\end{array}$ & $\begin{array}{l}\text { Clinical staff involve- } \\
\text { ment and collaboration }\end{array}$ \\
\hline
\end{tabular}

Table 2 Requirements for the selected causal analysis technique.

\begin{tabular}{|l|l|l|l|l|l|}
\hline Requirements & \multicolumn{3}{|l|}{ Causal analysis techniques } & & \\
\hline & $\begin{array}{l}\text { Bayesian } \\
\text { Networks }\end{array}$ & $\begin{array}{l}\text { Fuzzy Cogni- } \\
\text { tive Maps }\end{array}$ & $\begin{array}{l}\text { Interpretive Struc- } \\
\text { tural Modeling }\end{array}$ & DEMATEL & $\begin{array}{l}\text { Fuzzy } \\
\text { DEMATEL }\end{array}$ \\
\hline $\begin{array}{l}\text { Capable of represent- } \\
\text { ing all possible } \\
\text { connections among } \\
\text { CSFs }\end{array}$ & $\sqrt{ }$ & $\sqrt{ }$ & $\sqrt{ }$ & $\sqrt{ }$ \\
\hline $\begin{array}{l}\text { Processing uncertain } \\
\text { information }\end{array}$ & $\sqrt{ }$ & $\sqrt{ }$ & & & \\
\hline $\begin{array}{l}\text { Processing scarce in- } \\
\text { formation }\end{array}$ & & $\sqrt{ }$ & $\sqrt{ }$ & $\sqrt{ }$ \\
\hline $\begin{array}{l}\text { Variations in strength } \\
\text { of relationships } \\
\text { amongst CSFs and } \\
\text { two-way relationships }\end{array}$ & & & & $\sqrt{ }$ & $\sqrt{ }$ \\
\hline
\end{tabular}

\begin{tabular}{|l|l|}
\hline Linguistic terms & Triangular fuzzy numbers \\
\hline No influence & $(0,0,0.25)$ \\
\hline Very low influence & $(0,0.25,0.5)$ \\
\hline Low influence & $(0.25,0.5,0.75)$ \\
\hline High influence & $(0.5,0.75,1.0)$ \\
\hline Very high influence & $(0.75,1.0,1.0)$
\end{tabular}

Table 3 The fuzzy linguistic scale. 
Table 4 The overall direct-relation matrix Z.

\begin{tabular}{|c|c|c|c|c|c|c|c|c|c|c|c|c|c|c|c|c|c|c|c|c|c|c|c|}
\hline & $f_{1}$ & $f_{2}$ & $f_{3}$ & $f_{4}$ & $f_{5}$ & $f_{6}$ & $f_{7}$ & $f_{8}$ & $f_{9}$ & $f_{10}$ & $f_{11}$ & $f_{12}$ & $f_{13}$ & $f_{14}$ & $f_{15}$ & $f_{16}$ & $f_{17}$ & $f_{18}$ & $f_{19}$ & $f_{20}$ & $f_{21}$ & $f_{22}$ & $f_{23}$ \\
\hline$f_{1}$ & .000 & .334 & .447 & .447 & .447 & .167 & .000 & .125 & .000 & .391 & .000 & .334 & .000 & .302 & .167 & .000 & .000 & .302 & 167 & .167 & .198 & .250 & .188 \\
\hline$f_{2}$ & 00 & .000 & .625 & .208 & .854 & .688 & 688 & .759 & .816 & .406 & .406 & 677 & .167 & .354 & .559 & .302 & .563 & .559 & .458 & .406 & .447 & .559 & .631 \\
\hline$f_{3}$ & 00 & .458 & .000 & .616 & .458 & .563 & .542 & .503 & 677 & .616 & .688 & .631 & .503 & .802 & .672 & .250 & .583 & .510 & .583 & .616 & .503 & .616 & .344 \\
\hline$f_{4}$ & 302 & .000 & .250 & .000 & .250 & .000 & .167 & .125 & .000 & .125 & .208 & .198 & .208 & .156 & .000 & .302 & .616 & .000 & 167 & .167 & .125 & .000 & .000 \\
\hline$f_{5}$ & 302 & .447 & .688 & .406 & .000 & .875 & .759 & .759 & .631 & .688 & .406 & .354 & .354 & .616 & .391 & .278 & .677 & .559 & .688 & .563 & .744 & .542 & .802 \\
\hline$f_{6}$ & .000 & .167 & .406 & .000 & .631 & .000 & .631 & .616 & .559 & .503 & .672 & .616 & .391 & .616 & .559 & .250 & .500 & .616 & .503 & .391 & .447 & .334 & .269 \\
\hline$f_{7}$ & .000 & .000 & .292 & .125 & .292 & .510 & .000 & .510 & .510 & .500 & .510 & .510 & .208 & .292 & .458 & .000 & .583 & .802 & .510 & .510 & .406 & .583 & .688 \\
\hline$f_{8}$ & .000 & .631 & .302 & 167 & .406 & .744 & .500 & .000 & .563 & .000 & .583 & .000 & .000 & .510 & .000 & .125 & .167 & .688 & .292 & .458 & .688 & .631 & .678 \\
\hline$f_{g}$ & 000 & .000 & .616 & .616 & .559 & .759 & .688 & .503 & .000 & .406 & .250 & .406 & .000 & .000 & .510 & .000 & .278 & .759 & .616 & .616 & .616 & .616 & .759 \\
\hline$f_{10}$ & .000 & .000 & .510 & .000 & .406 & .354 & .292 & .575 & .354 & .000 & .750 & .406 & .334 & .816 & .744 & .616 & .208 & .510 & .250 & .458 & .250 & .406 & .575 \\
\hline$f_{11}$ & .000 & .354 & .406 & .000 & .000 & .406 & .542 & 167. & .250 & .447 & .000 & .354 & .334 & .750 & .750 & .616 & .563 & .816 & .672 & .583 & .563 & .510 & .688 \\
\hline$f_{12}$ & .000 & .000 & .000 & .000 & .000 & .198 & .125 & .510 & .000 & 125 & .458 & .000 & .510 & .458 & .510 & .167 & .000 & .250 & .000 & .631 & .000 & .250 & .000 \\
\hline$f_{13}$ & .000 & .000 & .208 & .167 & .000 & .167 & .208 & .208 & .000 & .447 & .575 & .406 & .000 & .744 & .672 & .000 & .000 & .000 & .000 & .458 & .302 & .559 & .391 \\
\hline$f_{14}$ & .208 & .250 & .406 & .208 & .302 & .302 & 167 & .447 & 208 & 677 & .575 & .167 & .250 & .000 & .672 & .000 & .391 & .167 & .000 & .542 & .447 & .542 & .354 \\
\hline$f_{15}$ & 167 & 208 & .406 & .000 & 292 & .333 & .354 & .354 & .302 & .406 & .503 & .447 & .250 & .354 & .000 & .167 & .302 & .391 & .447 & .447 & .334 & .391 & .391 \\
\hline$f_{16}$ & .000 & .000 & .000 & .000 & .125 & .125 & 167 & .125 & .125 & 292 & .354 & .250 & .672 & .729 & .677 & .000 & .000 & .208 & .250 & .406 & .503 & .559 & .302 \\
\hline$f_{17}$ & 167. & .125 & .458 & .729 & .208 & .167 & .302 & .125 & .000 & .000 & .302 & 167 & .250 & .510 & .000 & .198 & .000 & .559 & .447 & .559 & .208 & .503 & .447 \\
\hline$f_{18}$ & .125 & .302 & .559 & .406 & .406 & .447 & .631 & .406 & .447 & .302 & .302 & .334 & .000 & .302 & .167 & .334 & .559 & .000 & .688 & .744 & .559 & .802 & .744 \\
\hline$f_{19}$ & 167 & .250 & .354 & .250 & .354 & .250 & .503 & .559 & .503 & .000 & .354 & .000 & .447 & .250 & .406 & .198 & .503 & .631 & .000 & .744 & .559 & .927 & .678 \\
\hline$f_{20}$ & .000 & .250 & 167 & .458. & .391 & .334 & .458 & .354 & .391 & .503 & .250 & .000 & .391 & .447 & .000 & .447. & .503 & .447 & .625 & .000 & .672 & .802 & .678 \\
\hline$f_{21}$ & 198 & .510 & .406 & .302 & .458 & .510 & .559 & .616 & .503 & .406 & .406 & 198 & .198 & .354 & .354 & .125 & .354 & .447 & .688 & .616 & .000 & .616 & .448 \\
\hline$f_{22}$ & .125 & .391 & .559 & .447 & .250 & .354 & .458 & .447 & .302 & .559 & .391 & .125 & .125 & .391 & .616 & .198 & .458 & .559 & .688 & .631 & .616 & .000 & .759 \\
\hline$f_{23}$ & .198 & .354 & .559 & .447 & .503 & .391 & .802 & .729 & .616 & .559 & .631 & .447 & .354 & .503 & .616 & .391 & .503 & .575 & .503 & .688 & .503 & .759 & .000 \\
\hline
\end{tabular}


Table 5 The normalized direct-relation matrix N.

\begin{tabular}{|c|c|c|c|c|c|c|c|c|c|c|c|c|c|c|c|c|c|c|c|c|c|c|c|}
\hline & & 2 & & & 5 & $f_{6}$ & 7 & 8 & $f_{g}$ & 10 & $f_{11}$ & $f_{12}$ & 13 & $f_{14}$ & $f_{15}$ & 16 & $f_{17}$ & $f_{18}$ & $f_{19}$ & $f_{20}$ & $f_{21}$ & $f_{22}$ & $f_{23}$ \\
\hline & & 027 & 336 & 36 & 036 & 013 & 000 & .010 & 000 & 031 & .000 & 027 & .000 & .024 & 013 & .000 & .000 & .024 & .013 & .013 & .016 & 020 & 015 \\
\hline & & 00 & & & 068 & 55 & 55 & 061 & 65 & 32 & .032 & 54 & 13 & .028 & 345 & 24 & .045 & 45 & 037 & .032 & .036 & 045 & .050 \\
\hline & & 37 & 00 & 49 & .037 & 45 & 43 & 040 & 54 & 49 & .055 & 50 & 40 & .064 & 054 & 020 & .047 & 41 & 047 & .049 & .040 & 49 & 027 \\
\hline & & 00 & 20 & 00 & .020 & 00 & 13 & .010 & 00 & & .017 & 16 & 17 & .012 & 000 & 024 & .049 & 000 & 013 & .013 & .010 & 000 & .000 \\
\hline 5 & & 36 & נטנס & & .000 & 70 & 61 & .061 & 50 & 55 & .032 & .028 & .028 & .049 & .031 & .022 & .054 & .045. & .055 & .045 & .059 & .043 & .064 \\
\hline & & & 37 & & 050 & مח & 50 & .049 & 4 & 40 & .054 & 049 & .031 & 049 & 045 & .020 & $0 \triangle 0$ & 049 & 040 & .031 & .036 & .027. & .021 \\
\hline & & no & 23 & & 023 & & 00 & 041 & 1 & & 041 & 1 & 017 & 023 & 037 & .000 & 047 & .064 & .041. & .041 & .032 & 47 & 055 \\
\hline & & 50 & 24 & 13 & 032 & 259 & 40 & .000 & 045 & 00 & .047 & .000 & 000 & .041 & .000 & .010 & .013 & .055 & 023 & .037 & .055 & 050 & .054 \\
\hline & 00 & .000 & 49 & 49 & .045 & 061 & 55 & .040 & .000 & 032 & .020 & .032 & .000 & .000 & .041 & .000 & .022 & .061 & .049 & .049 & .049 & .049 & .061 \\
\hline$t_{10}$ & 00 & 00 & 41 & 00 & .032 & 28 & 23 & .046 & .028 & 00 & .060 & .032 & .027 & .065 & .059 & .049 & .017 & .041 & .020 & .037 & .020 & .032 & .046 \\
\hline$t_{11}$ & 0 & 28 & 32 & 00 & 00 & 32 & (4) & & $\angle 0$ & 36 & . & 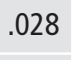 & .027 & 0 & .060 & .049. & .045 & .065 & 54 & .047 & .045 & .041. & .055 \\
\hline & ח & 00 & 00 & ח & .000 & 16 & & .041 & ov & & 037 & חمחל & & 027 & ודם. & .013. & 00 & .020 & . 000 & .050 & .000 & 20 & 000 \\
\hline$f_{13}$ & ח०ח & $0 \cap 0$ & 17 & 013 & 000 & 013 & 017 & 017 & 000 & .036 & $0 \triangle 6$ & 032 & .000 & 059 & .054. & .000 & .000 & .000 & .000 & .037 & .024 & .045 & .031 \\
\hline$f_{14}$ & 17 & م?0 & 032 & 17 & .024 & 024 & .013 & .036 & .017 & .054 & .046 & .013. & .020 & .000 & .054 & .000 & .031 & .013 & .000 & .043 & .036 & .043 & .028 \\
\hline$f_{15}$ & & 17 & 32 & 00 & .023 & 27 & 28 & .028 & . 024. & .032 & .040 & .036. & .020 & .028 & .000 & .013 & .024 & .031 & .036 & .036 & .027 & .031 & .031 \\
\hline & 0 & 00 & 0 & 00 & & 10 & & & 10 & & .028 & 20 & & 58 & 54 & .000 & .000 & 017 & 20 & 032 & .040 & 45 & 024 \\
\hline & J & & 37 & 58 & & 013 & & & .000 & & & .013 & .020 & .041 & .000 & .016 & .000 & .045 & .036 & .045 & .017 & .040 & .036 \\
\hline$f_{18}$ & 10 & .024 & 45 & 32 & .032 & .036 & .050 & .032 & (050. & .024 & .024 & .027 & .000 & .024 & .013 & .027 & .045 & .000 & .055 & .059 & .045 & .064 & .059 \\
\hline$f_{19}$ & & חבר & 20 & 20 & $.0<0$ & חבק & .040 & .045 & .040 & .000 & $.0<0$ & .000 & .036 & $.0<0$ & .032 & .016 & .040 & .050 & .000 & .059 & .045 & .074 & .054 \\
\hline 20 & 00 & .02 & (2) & 37 & .031 & .027 & .037 & .028 & .031 & .040 & .020 & .000 & .031 & .036 & .000 & .036 & .040 & .036 & .050 & .000 & .054 & .064 & .054 \\
\hline$f_{21}$ & & .041 & 032 & .024 & .037 & SI & 45 & .049 & .040 & .032 & .032 & .016. & .016 & .028 & .028 & .010 & .028 & .036 & .055 & .049 & .000 & .049 & .036 \\
\hline$f_{22}$ & .010 & .031 & .045 & .036 & .020 & .028 & .037 & .036 & .024 & .045 & .031 & .010 & .010 & .031 & .049 & .016 & .037 & .045 & .055 & .050 & .049 & .000 & .061 \\
\hline$f_{23}$ & .016 & .028 & .045 & .036 & .040 & .031 & .064 & .058 & .049 & .045 & .050 & .036 & .028 & .040 & .049 & .031 & .040 & .046 & .040 & .055 & .040 & .061 & .000 \\
\hline
\end{tabular}


Table 6 The total-relation matrix T.

\begin{tabular}{|c|c|c|c|c|c|c|c|c|c|c|c|c|c|c|c|c|c|c|c|c|c|c|c|}
\hline & $f_{1}$ & $t_{2}$ & $f_{3}$ & $f_{4}$ & $f_{5}$ & $f_{6}$ & $f_{7}$ & $f_{8}$ & 9 & $f_{10}$ & $f_{11}$ & $f_{12}$ & $f_{13}$ & $f_{14}$ & $f_{15}$ & $f_{16}$ & $f_{17}$ & $f_{18}$ & $f_{19}$ & $f_{20}$ & $f_{21}$ & $f_{22}$ & $f_{23}$ \\
\hline$f_{1}$ & 009 & 049 & 071 & 060 & 067 & .050 & 041 & 052 & .035 & .066 & 041 & .054 & .025 & .065 & .052 & .023 & .038 & .066 & .053 & .061 & .056 & .068 & .060 \\
\hline$f_{2}$ & 21 & 56 & 40 & 081 & 45 & 48 & .160 & 62 & 150 & 120 & 34 & 123 & .075 & 132 & .141 & .077 & 136 & .158 & 139 & 154 & .140 & 169 & 167 \\
\hline t. & 2) & 90 & 91 & 10 & 14 & 135 & 146 & 40 & 136 & 135 & 55 & 118 & 101 & 66 & 150 & .074 & 137 & 151 & 146 & 170 & 143 & 173 & .144 \\
\hline$t_{4}$ & 30 & 15 & 43 & 018 & 39 & 24 & .039 & 35 & 021 & .033 & 43 & 034 & .034 & 42 & .026 & .038 & 071 & .030 & .039 & .046 & .037 & .034 & .031 \\
\hline$f_{5}$ & & 97 & 53 & 103 & 89 & 169 & .174 & 71 & .145 & 149 & 45 & .105 & .095 & .162 & .138 & .081 & .153 & .168 & .165 & .177 & .172 & .181 & 190 \\
\hline$T_{6}$ & & 61 & 100 & 054 & 114 & 081 & .138 & 135 & .116 & .114 & 140 & .107 & .083 & 138 & .128 & .066 & .116 & 144 & .126 & .136 & .125 & .135 & .123 \\
\hline 1 & & 45 & 295 & 061 & 884 & 2112 & .084 & 20 & 107 & 107 & 120 & .093 & .064 & 105 & .111 & .044 & .118. & 151 & .121 & 137. & 114 & .145 & .146 \\
\hline $\boldsymbol{f}_{\varepsilon}$ & 117 & 94 & 097 & .064 & .096 & 132 & 124 & 082 & 114 & .071 & 123 & .056 & .047 & 118 & .077 & .052 & .088. & 142 & .106 & 131 & 137 & .148 & .146 \\
\hline$f_{9}$ & 19 & 50 & .126 & .104 & 13 & .139 & .146 & 29 & .077 & 107 & 108 & .092 & .054 & .090 & .121 & .049 & .104 & .157 & 139 & .153 & .138 & .156 & .160 \\
\hline$f_{10}$ & 16 & 45 & 109 & .048 & 991 & .099 & .104 & 122 & .094 & .070 & 138 & .086 & .075 & .146 & .136 & .090 & .087 & .126 & .098 & .131 & .103 & .130 & .136 \\
\hline$f_{11}$ & & 75 & 108 & .055 & 68 & 108 & 130 & 00 & .093 & .110 & 088 & .087 & .080 & .147 & .143 & .094 & .121 & 157 & .139 & 151 & .133 & .149 & .153 \\
\hline$f_{12}$ & 007 & 20 & .031 & .020 & 026 & 017 & .045 & 073 & .029 & .042 & בד0 & .023 & .061. & . 074. & .074 & .033 & .031 & .058 & .035 & .091 & .038 & .064 & .043 \\
\hline$f_{13}$ & 010 & .027 & .059 & 041 & 036 & .056 & .064 & .064 & .040 & .079 & 095 & .064 & .030 & .109 & .101 & .027 & .043 & .053 & .048 & .093 & .072 & .102 & .085 \\
\hline$f_{14}$ & 030 & .057 & .091 & .057 & .075 & .084 & .081 & .100 & .072 & .110 & .111 & .059 & .059 & .070 & .115 & .037 & .090 & .086 & .068 & .120 & .102 & .122 & .104 \\
\hline$f_{15}$ & 126 & 53 & 90 & .042 & 73 & 86 & .095 & 94 & .079 & .089 & 105 & .080 & .060 & .096 & .064 & .049 & .083 & .104. & .101 & .114 & .094 & . 113 & .107 \\
\hline$f_{16}$ & & 28 & 45 & .030 & 47 & 55 & 64 & 61 & 51 & .069. & 80 & .054 & .083. & 10 & .104 & .027 & .045 & .070 & 069 & .093 & .091 & 107 & .083 \\
\hline$f_{17}$ & .026 & 41 & .085 & .094 & .059 & .062 & .080 & 065 & .047 & .049 & .078 & .050 & .054 & .096 & .053 & .046 & .053 & .102 & .090 & .110 & .074 & 108 & .098 \\
\hline$f_{18}$ & .028 & .072 & .121 & .089 & .100 & .174 & .139 & .119 & .109 & .099 & .110 & .085 & .054 & .112 & .096 & .073 & .124 & .098 & .142 & .162 & .134 & .170 & .158 \\
\hline$f_{19}$ & 10 & .066 & .101 & .074 & וכט. & .084 & .124 & 121 & .100 & .072 & .100 & .055 & .082 & .102 & .107 & .058 & .114 & .139 & .085 & 155 & .129 & .173 & .148 \\
\hline 20 & .011 & .062 & .084 & .086 & .091 & .096 & .116 & 05 & .096 & .106 & .097 & .052 & .077 & .114 & .076 & .076 & .110 & .120 & .126 & .094 & .132 & .158 & .143 \\
\hline$f_{21}$ & .033 & .087 & 108 & .078 & 03 & .118 & .132 & .133 & .113 & 105 & .116 & .074 & .066 & .114 & .108 & .056 & .106 & .130 & .139 & .149 & .089 & .153 & .135 \\
\hline$f_{22}$ & .028 & .078 & .120 & .089 & .088 & .105 & .125 & .121 & .098 & .117 & .116 & .069 & .062 & .118 & .128 & .063 & .115 & .138 & .140 & .151 & .136 & .108 & .157 \\
\hline$f_{23}$ & .037 & .084 & .135 & .099 & .118 & .124 & .166 & .158 & .134 & .132 & .151 & .105 & .089 & .144 & .145 & .085 & .132 & .158 & .143 & .176 & .145 & .185 & .120 \\
\hline
\end{tabular}


Table 7 The degree of prominence and net cause/effect of CSFs.

\begin{tabular}{|c|c|c|c|c|}
\hline Factor & $\mathbf{R}$ & D & Prominence $\mathbf{D}+\mathrm{R}$ & Net effect R-D \\
\hline$f_{1}$ & 1.160 & 0.519 & 1.679 & 0.641 \\
\hline$f_{2}$ & 2.929 & 1.354 & 4.283 & 1.575 \\
\hline$f_{3}$ & 2.949 & 2.213 & 5.162 & 0.736 \\
\hline$f_{4}$ & .801 & 1.558 & 2.360 & -0.757 \\
\hline$f_{5}$ & 3.230 & 1.927 & 5.157 & 1.304 \\
\hline$f_{6}$ & 2.506 & 2.238 & 4.745 & 0.268 \\
\hline$f_{7}$ & 2.304 & 2.515 & 4.819 & -0.212 \\
\hline$f_{8}$ & 2.261 & 2.465 & 4.726 & -0.204 \\
\hline$f_{9}$ & 2.531 & 2.063 & 4.594 & 0.468 \\
\hline$f_{10}$ & 2.281 & 2.150 & 4.431 & 0.131 \\
\hline$f_{11}$ & 2.506 & 2.477 & 4.983 & 0.030 \\
\hline$f_{12}$ & 1.039 & 1.726 & 2.765 & -0.687 \\
\hline$f_{13}$ & 1.397 & 1.512 & 2.909 & -0.115 \\
\hline$f_{14}$ & 1.900 & 2.570 & 4.470 & -0.671 \\
\hline$f_{15}$ & 1.898 & 2.394 & 4.292 & -0.495 \\
\hline$f_{16}$ & 1.478 & 1.318 & 2.796 & 0.160 \\
\hline$f_{17}$ & 1.621 & 2.213 & 3.835 & -0.592 \\
\hline$f_{18}$ & 2.508 & 2.706 & 5.214 & -0.198 \\
\hline$f_{19}$ & 2.339 & 2.457 & 4.797 & -0.118 \\
\hline$f_{20}$ & 2.232 & 2.955 & 5.188 & -0.723 \\
\hline$f_{21}$ & 2.445 & 2.536 & 4.981 & -0.090 \\
\hline$f_{22}$ & 2.471 & 3.051 & 5.522 & -0.580 \\
\hline$f_{23}$ & 2.966 & 2.837 & 5.803 & 0.129 \\
\hline
\end{tabular}




\section{References}

1. Campbell H, Hotchkiss R, Bradshaw N, Porteous M. Integrated care pathways. BMJ 1998; 316(7125): 133-137.

2. Hunter B, Segrott J. Re-mapping client journeys and professional identities: a review of the literature on clinical pathways. Int J Nurs Stud 2008; 45(4): 608-625.

3. Schuld J, Schäfer T, Nickel S, Jacob P, Schilling MK, Richter S. Impact of IT supported clinical pathways on medical staff satisfaction. A prospective longitudinal cohort study. Int J Med Inform 2011; 80(3): 151-156.

4. Huang Z, Lu X, Duan H. On mining clinical pathway patterns from medical behaviors. Artificial Intelligence in Medicine 2012; 56(1): 35-50.

5. Huang Z, Lu X, Duan H, Fan W. Summarizing clinical pathways from event logs, Journal of Biomedical Informatics 2013; 46(1): 111-127.

6. Panella M, Marchisio S, Di Stanislao F. Reducing clinical variations with clinical pathways: do pathways work? Int J Qual Health Care 2003; 15(6): 509-521.

7. Huang Z, Lu X, Duan H. Anomaly detection in clinical processes. AMIA Annu Symp Proc 2012; 370-379.

8. Li H. Informationazation is the foundation to achieve the standard management of clinical pathway. China Digit Med 2010; 5(10): 1.

9. Renholm M, Leino-Kilpi H, Suominen T. Critical pathways: a systematic review. Journal of Nursing Administration 2002; 32(4): 196-202.

10. Verhelst D, Nachtergaele M, Hindryckx C, Vandevyvere V, Seghers S, Smessaert K, Vanderschueren S. Can a care pathway help streamline the care process for patients with chronic fatigue syndrome? International Journal of Care Pathways 2011; 15(4): 115-118.

11.Vanhaecht K, Panella M, Van Zelm R, Sermeus W. Is there a future for pathways? Five pieces of the puzzle. International Journal of Care Pathways 2009; 13(2): 82-86.

12. Choo J. Critical success factors in implementing clinical pathways/case management. Ann Acad Med Singapore 2001; 30(4): 17-21.

13. Rotter T, Kinsman L, James EL, Machotta A, Gothe H, Willis J, Snow P, Kugler J. Clinical pathways: effects on professional practice, patient outcomes, length of stay and hospital costs. Eval Health Prof 2012; 35(1): 3-27.

14. Emmerson B, Frost A, Fawcett L, Ballantyne E, Ward W, Catts S. Do clinical pathways really improve clinical performance in mental health settings?” Australasian Psychiatry 2006; 14(4): 295-398.

15. Shi J, Su Q, Zhao Z. Critical factors for the effectiveness of clinical pathway in improving care outcomes. Service Systems and Service Management 2008; 1-6.

16. Evans-Lacko S, Jarrett M, McCrone P, Thornicroft G. Facilitators and barriers to implementing clinical care pathways. BMC Health Services Research 2010; 10: 182.

17. Pace KB, Sakulkoo S, Hoffart N, Cobb AK. Barriers to successful implementation of a clinical pathway for CHF. Journal for Healthcare Quality 2002; 24(5): 32-38.

18. Wu WW. Segmenting critical factors for successful knowledge management implementation using the fuzzy DEMATEL method. Applied Soft Computing 2012; 12(1): 527-535.

19. Vanhaecht K, Bollmann M, Bower K, Gallagher C, Gardini A, Guezo J, Jansen U, Massoud R, Moody K, Sermeus W, van Zelm R, Whittle C, Yazbeck AM, Zander K, Panella M. International survey on the use and dissemination of clinical pathways in 23 countries. Journal of Integrated Care Pathways 2006; 10(1): 28-34.

20. Guo S, Tao H, Qu H, Ke X, Liu P, Liang J. Analysis of key links of the medical service process under the management mode of clinical pathway. Chinese Journal of Hospital Administration 2009; 25(12): 808-811.

21. Haddock CC, McLean RD. Careers in Healthcare Management: How to Find your Path and Follow It. Chicago: Health Administration Press 2002.

22. Huang Z, Lu X, Duan H, Zhao C. Collaboration-based medical knowledge recommendation. Artificial Intelligence in Medicine 2012; 55(1): 13-24.

23. Hu P, Wang Y, Lu J, Li D, Zhang W. Impacting factors and suggestions on implementing clinical pathway. Chinese Journal of Hospital Administration 2012; 28(1): 15-18.

24. Rigby M. Citation Analysis in Health Care Sciences. Methods Inf Med 2014; 53(6): 459-463.

25. Reeder B, Chung J, Le T, Thompson H, Demiris G. Analytic Hierarchy Process (AHP) for Examining Healthcare Professionals' Assessments of Risk Factors. Methods Inf Med 2011; 50(5): 435-444.

26. Abdullah L, Zulkifli N. Integration of fuzzy AHP and interval type-2 fuzzy DEMATEL: An application to human resource management. Expert Systems with Applications 2015; 42(9): 4397-4409.

27. Wu WW, Lee YT. Developing global manager's competencies using the fuzzy EDEMATEL method. Expert Systems with Applications 2007; 32(2): 499-507. 
28. Tseng ML. Using the extension of DEMATEL to integrate hotel service quality perceptions into a cause-effect model in uncertainty. Expert Systems with Applications 2009; 36(5): 9015-9023.

29. Opricovic S, Tzeng GH. Defuzzification within a multicriteria decision model. International Journal of Uncertainty Fuzziness and Knowledge-Based Systems 2003; 11(5): 635-652.

30.Dai J, Tao HB, Yu Y. The significance and prospects of medical institution surveillance by applying clinical pathways to control medical quality. Chinese Hospital Management 2008; 28 (7): 14-15.

31. Gooch P, Roubsari A. Computerization of workflows, guidelines, and care pathways: a review of implementation challenges for process-oriented health information systems. J Am Med Inform Assoc 2011; 18(6): 738-748.

32. Defossez G, Rollet A, Dameron O, Ingrand P. Temporal representation of care trajectories of cancer patients using data from a regional information system: An application in breast cancer. BMC Medical Informatics and Decision Making 2014; 14: 24.

33. Huang Z, Dong W, Duan H, Li H. Similarity measure between patient traces for clinical pathway analysis: problem, method, and applications. IEEE J Biomed Health Inform 2014; 18(1): 4-14.

34. Huang Z, Dong W, Ji L, Gan C, Lu X, Duan H. Discovery of clinical pathway patterns from event logs using probabilistic topic models. J Biomed Inform 2014; 47: 39-57.

35.Sung K, Chung C, Lee K, Lee S, Ahn S, Park S, Choi I, Cho TJ, Yoo W, Lee J, Park M. Application of clinical pathway using electronic medical record system in pediatric patients with supracondylar fracture of the humerus: a before and after comparative study. BMC Medical Informatics and Decision Making 2013; 13: 87.

36. Huang Z, Dong W, Bath P, Ji L, Duan H. On mining latent treatment patterns from electronic medical records. Data Mining and Knowledge Discovery 2015; 29(4): 914-949.

37.Patil SK, Kant R. A hybrid approach based on fuzzy DEMATEL and FMCDM to predict success of knowledge management adoption in supply chain. Applied Soft Computing 2014; 18: 126-135.

38. Abdekhoda M, Ahmadi M, Dehnad A, Hosseini AF. Information Technology Acceptance in Health Information Management. Methods Inf Med 2014; 53(1): 14-20.

39. Govindan K, Khodaverdi R, Vafadarnikjoo A. Intuitionistic fuzzy based DEMATEL method for developing green practices and performance in a green supply chain. Expert Systems with Applications 2015; 42(20): 7207-7220.

40.Li Y, Hu Y, Zhang X, Deng Y, Mahadevan S. An evidential DEMATEL method to identify critical success factors in emergency management. Applied Soft Computing 2014; 22: 504-510. 